\title{
BMJ Open Calculating the burden of disease of avian-origin H7N9 infections in China
}

Xiaopeng Qi, ${ }^{1}$ Dong Jiang, ${ }^{2}$ Hongliang Wang, ${ }^{3}$ Dafang Zhuang, ${ }^{2}$ Jiaqi Ma, ${ }^{1}$ Jingying Fu, ${ }^{2,4}$ Jingdong Qu, ${ }^{3}$ Yan Sun, ${ }^{5}$ Shicheng Yu, ${ }^{1}$ Yujie Meng, ${ }^{1}$ Yaohuan Huang, ${ }^{2}$ Lanfang Xia, ${ }^{1}$ Yingying Li, ${ }^{1}$ Yong Wang, ${ }^{2}$ Guohua Wang, ${ }^{5}$ Ke Xu, ${ }^{6}$ Qun Zhang, ${ }^{1}$ Ming Wan, ${ }^{1}$ Xuemei Su, ${ }^{1}$ Gang Fu, ${ }^{1}$ George F Gao ${ }^{7}$

To cite: Qi X, Jiang D, Wang $\mathrm{H}$, et al. Calculating the burden of disease of avianorigin H7N9 infections in China. BMJ Open 2014;4: e004189. doi:10.1136/ bmjopen-2013-004189

- Prepublication history and additional material for this paper is available online. To view these files please visit the journal online (http://dx.doi.org/10.1136/ bmjopen-2013-004189).

$\mathrm{XQ}, \mathrm{DJ}, \mathrm{HW}, \mathrm{DZ}$ and JM contributed equally.

Received 9 October 2013 Revised 22 November 2013 Accepted 20 December 2013

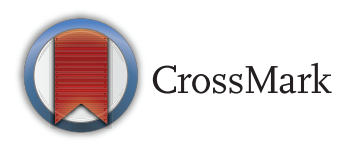

For numbered affiliations see end of article.

Correspondence to Dr Xiaopeng Qi; qixp@chinacdc.cn or Prof George F Gao; gaofu@chinacdc.cn

\section{ABSTRACT}

Objective: A total of 131 cases of avian-originated H7N9 infection have been confirmed in China mainland from February 2013 to May 2013. We calculated the overall burden of H7N9 cases in China as of 31 May 2013 to provide an example of comprehensive burden of disease in the 21st century from an acute animalborne emerging infectious disease.

Design: We present an accurate and operable method for estimating the burden of H7N9 cases in China. The main drivers of economic loss were identified. Costs were broken down into direct (outpatient and inpatient examination and treatment) and indirect costs (cost of disability-adjusted life years (DALYs) and losses in the poultry industry), which were estimated based on field surveys and China statistical year book.

Setting: Models were applied to estimate the overall burden of H7N9 cases in China.

Participants: 131 laboratory-confirmed H7N9 cases by 31 May 2013.

Outcome measure: Burden of H7N9 cases including direct and indirect losses.

Results: The total direct medical cost was $¥ 16422535$ (US\$2 627606 ). The mean cost for each patient was $¥ 10117$ (US\$1619) for mild patients, $¥ 139323$ (US\$22 292) for severe cases without death and $¥ 205976$ (US\$32 956) for severe cases with death. The total cost of DALYs was $¥ 17356561$ (US $\$ 2777050$ ). The poultry industry losses amounted to $¥ 7.75$ billion (US\$1.24 billion) in 10 affected provinces and $¥ 3.68$ billion (USD\$0.59 billion) in eight nonaffected adjacent provinces.

Conclusions: The huge poultry industry losses followed live poultry markets closing down and poultry slaughtering in some areas. Though the proportion of direct medical losses and DALYs losses in the estimate of H7N9 burden was small, the medical costs per case were extremely high (particularly for addressing the use of modern medical devices). A cost-effectiveness assessment for the intervention should be conducted in a future study.

\section{INTRODUCTION}

A novel avian-origin influenza A (H7N9) virus has caused severe disease in humans in China since February 2013. The high number of new

\section{Strengths and limitations of this study}

- This study is the first in which comprehensive methods were applied to identify the main drivers of economic losses and estimate the burden of disease due to H7N9 infection including direct costs (medical cost) and indirect costs (death, disability, and poultry-industry losses);

- This study had some limitations. The estimate of medical costs was based on a model and second-hand data, not on the original costs of patients with H7N9. The burden of H7N9 may have been underestimated, as the ongoing costs of existing cases and new cases after May 2013 were underreported and other losses involved in the livestock-production chain were not included in our study.

cases within a short period and the high-case death rate have caused public panic and attracted global attention. Some patient's families undertook large medical costs. According to the literature, exposure to live poultry could be an important risk factor for human infection with H7N9. ${ }^{1-5}$ As a result, closing down the live poultry markets and slaughtering the poultry were the main interventional measures in the affected areas of China. These interventions not only played an important role in disease prevention but also caused serious losses to the poultry industry.

The introduction of the novel virus led to numerous investigations of its origin, its genes, clinical symptoms, laboratory testing, treatment and transmission ${ }^{6-8}$; however, the burden of human infection with H7N9 has not yet been measured. It is important to estimate the overall burden of disease (BOD) due to H7N9 in China because this virus is new to humans and could cause a global pandemic in the future. The Global Burden of Disease (GBD) 2010 study presents a comprehensive methodological framework for death and disability loss estimation and has had a pronounced impact on the 
BOD estimate. ${ }^{9}{ }^{10}$ In this study, we identified the main drivers of economic loss and summarised the direct and indirect costs of human H7N9 infection. We present an accurate and operable approach for estimating the overall burden of emerging infectious diseases and provide evidence on the cost-effectiveness of H7N9 prevention and control. We also set up a BOD estimate example for any animal-borne infectious disease, particularly with the introduction of modern medical devices.

\section{METHODS}

\section{Case category definition}

The confirmed human H7N9 infections were divided into mild and severe cases based on the 'Diagnostic and treatment protocol for human infections with avian influenza A (H7N9) (2nd edition, 2013), ${ }^{11}$ Mild cases presented with influenza-like illness, whereas severe cases developed quickly and presented with severe pneumonia, usually accompanied by severe complications and organ failure. Severe illness was divided into 'severe without death' and 'severe with death'. The 11 H7N9 cases of unknown status were classified as 'unknown without death'.

\section{Data source}

Data on the 131 confirmed H7N9 cases by the end of 31 May 2013 came from China Information System for Diseases Control and Prevention and included basic information on the onset of illness, epidemiology and emergency event reporting. Disability-adjusted life years (DALYs) were calculated based on two published sources. The WHO provided a table of life expectancy by age for China in $2011,{ }^{12}$ whereas the Institute for Health Metrics and Evaluation (IHME) published the GBD 2010, including the GBD 2010 Disability weights. ${ }^{13}$ Disability weights of general infectious disease (acute episode for mild, moderate and severe) were adopted from IHME based on clinician's suggestions of symptoms from H7N9 cases that were more severe than the general infectious disease cases. The 2012 per capita gross domestic product (GDP), which was used to calculate the cost of lost lives and the cost of disability, was obtained from the National Bureau of Statistics of China.

Poultry production and trade data from 27 prefectures with confirmed H7N9 cases, including live poultry sales, dates of live-market closings and market-stall volumes were collected from field surveys, local livestock-breeding year book ${ }^{14}$ and the Chinese Commodities Trading-Market Statistics Yearbook $2012 .{ }^{15}$ Data were gathered from the 10 affected provinces and 8 unaffected adjacent provinces. These data were used to estimate poultry industry losses (PIL).

\section{Analysis framework for the burden of confirmed H7N9 cases}

We constructed a framework for the BOD analysis (figure 1). We described the confirmed H7N9 cases as mild, severe without death, severe with death and

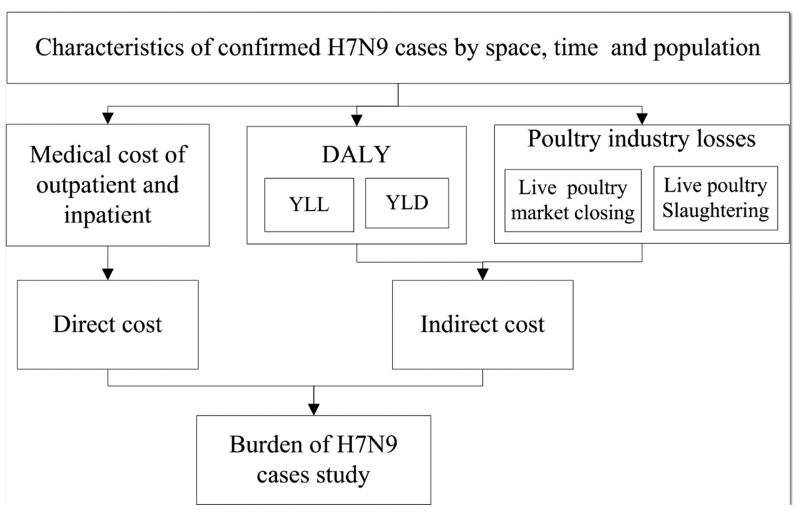

Figure 1 Framework for calculating the burden of confirmed $\mathrm{H} 7 \mathrm{~N} 9$ cases, describing the analytical route of direct and indirect costs, which were integrated into the overall burden of confirmed $\mathrm{H} 7 \mathrm{~N} 9$ cases. The framework was drawn using the Microsoft Office Visio 2003 software. DALY, disability-adjusted life years; YLD, years lived with disability; YLL, years of life loss.

unknown without death and examined the spatiotemporal and population characteristics of these cases. Based on the case category and characteristics of case spatiotemporal distribution, costs were broken down into direct medical costs (outpatient and inpatient examination and treatment) and indirect costs (death, disability and PIL). To calculate the DALYs attributable to H7N9, the H7N9-specific years of life loss due to premature mortality (YLLs) and years lived with disability (YLDs) were computed and summed. An intensive analysis of PIL would be complex and would require timeconsuming field surveys. Indirect effects may lag behind. In this study, we considered only the PIL caused from the closing of live poultry markets and the large-scale slaughtering of poultry.

\section{Statistical analysis}

Descriptive statistics were used to summarise the epidemiological characteristics of the cases. The distribution of confirmed H7N9 cases by week was also extracted by creating two SD ellipses (covering $95 \%$ of the points while calculating the $\mathrm{SD}$ of the $\mathrm{x}$-coordinates and y-coordinates from the mean centre to define the axes of the ellipse) to summarise the spatial spread of confirmed H7N9 cases (central tendency, dispersion and directional trends). If the number of cases in 1 week was less than three, those cases were not included in the calculation.

The methods for estimating direct medical costs are traditionally classified into two broad approaches: bottom-up (microcosting) and topdown (macrocosting). ${ }^{16}{ }^{17}$ In general, the bottom-up approach usually results in a higher but more accurate estimate. ${ }^{18}$ In our study, we used the bottom-up approach to estimate direct medical costs. Four cost drivers were extracted: cost of outpatient and inpatient examinations in the ward, cost of examinations in intensive care units (ICUs), cost of 
Table 1 Formula for calculating direct medical costs

\begin{tabular}{|c|c|}
\hline Cost & Formula \\
\hline $\begin{array}{l}\text { Cost of examination for outpatient and inpatient in ward (laboratory } \\
\text { and radiology) }\end{array}$ & Cost per patient $\times$ number of patients \\
\hline Cost of examination in ICU (laboratory and radiology) & $\begin{array}{l}\text { Cost per day } \times \text { mean number of days of ICU } \\
\text { stay } \times \text { number of patients }\end{array}$ \\
\hline \multicolumn{2}{|l|}{ Cost of treatment } \\
\hline Antiviral & Cost per day $\times$ mean number of days $\times$ number of patients \\
\hline Antibiotics & Cost per day $\times$ mean number of days $\times$ number of patients \\
\hline Other drugs & Cost per day $\times$ mean number of days $\times$ number of patients \\
\hline Glucocorticoids & Cost per day $\times$ mean number of days $\times$ number of patients \\
\hline Intravenous immunoglobulin & Cost per day $\times$ mean number of days $\times$ number of patients \\
\hline Oxygen therapy & $\begin{array}{l}\text { Cost per day } \times \text { mean number of days of hospital } \\
\text { stay } \times \text { number of patients }\end{array}$ \\
\hline ICU care & $\begin{array}{l}\text { Cost per day } \times \text { mean number of days of ICU } \\
\text { stay } \times \text { number of patients }\end{array}$ \\
\hline ICU monitor & $\begin{array}{l}\text { Cost per day } \times \text { mean number of days of ICU } \\
\text { stay } \times \text { number of patients }\end{array}$ \\
\hline \multicolumn{2}{|l|}{ Mechanical ventilation } \\
\hline Non-invasive & Cost per day $\times$ mean number of days $\times$ number of patients \\
\hline Invasive & Cost per day $\times$ mean number of days $\times$ number of patients \\
\hline Artificial-liver-support-system therapy & Cost per day $\times$ mean number of days $\times$ number of patients \\
\hline Continuous renal-replacement therapy & Cost per day $\times$ mean number of days $\times$ number of patients \\
\hline ECMO & Cost per day $\times$ mean number of days $\times$ number of patients \\
\hline \multicolumn{2}{|r|}{ 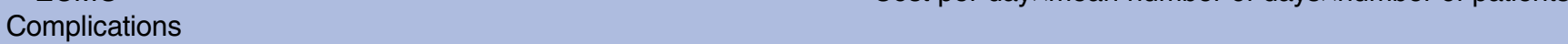 } \\
\hline ARDS & $\begin{array}{l}\text { Cost per day } \times \text { mean number of days of ICU } \\
\text { stay } \times \text { number of patients }\end{array}$ \\
\hline Shock & $\begin{array}{l}\text { Cost per day } \times \text { mean number of days of ICU } \\
\text { stay } \times \text { number of patients }\end{array}$ \\
\hline Acute kidney injury & $\begin{array}{l}\text { Cost per day } \times \text { mean number of days of ICU } \\
\text { stay } \times \text { number of patients }\end{array}$ \\
\hline Rhabdomyolysis & $\begin{array}{l}\text { Cost per dayxmean number of days of ICU } \\
\text { stayxnumber of patients }\end{array}$ \\
\hline Other costs* & $\begin{array}{l}\text { Cost per day } \times \text { mean number of days of hospital } \\
\text { stay } \times \text { number of patients }\end{array}$ \\
\hline
\end{tabular}

*Other costs include medical consumables, charge for sickbed, general care services, check-up fees, etc.

ARDS, acute respiratory distress syndrome; EMCO, extracorporeal membrane oxygenation; ICU, intensive care unit.

treatment and other costs (including medical consumables, charge for sickbed, general care services, check-up fee, etc). A cost formula was constructed for each driver, as depicted in table 1 . The cost per patient was estimated by experienced hospital financial officers and hospital doctors. The mean number of days (ICU stay, hospital stay and days of treatment) was estimated from the epidemiological data. The number of patients for each driver was derived from a previous publication. ${ }^{6}$ The professional's experience was also considered for some items that were not included in our surveillance system. Costs for the category 'unknown without death' were assumed to be moderate and were set as the average of the costs of mild cases and severe cases without death.

The YLLs for confirmed H7N9 cases in China were calculated from the sum of the number of fatal cases (n) in 5-year age groups (i) multiplied by the remaining expected life span (e) based on the age of death for that age group ${ }^{19}$ : (formula 1 )

$$
\text { YLLs }=\sum \mathrm{n}_{\mathrm{i}} \times \mathrm{e}_{\mathrm{i}}
$$

The Chinese life-expectancy table from WHO 2011 was used to estimate the burden of H7N9 in YLLs.

The YLDs were calculated by multiplying the duration of illness ( $\mathrm{t}$ ) by the disability weights (w) accumulated over all H7N9 cases (d) for each health outcome (j) (formula 2)

$$
\text { YLDs }=\Sigma \mathrm{d}_{\mathrm{j}} \times \mathrm{t}_{\mathrm{j}} \times \mathrm{w}_{\mathrm{j}}
$$

As H7N9 is a relatively new infectious disease and the health status of patients after discharge is unknown, we calculated the YLDs only as general acute episodes of infectious disease during the hospital stay. Disability weights were assigned as infectious disease disability weight (mild, moderate and severe acute episodes). ${ }^{13}$

DALYs were calculated by adding YLLs to morbidity and disability, expressed in YLD (formula 3)

$$
\text { DALYs }=\text { YLLs }+ \text { YLDs }
$$

An estimate of the cost of one DALY was based on the traditional human-capital approach for per capita GDP 
Table 2 Formula for calculating poultry-industry losses

\begin{tabular}{|c|c|}
\hline Cost & Formula \\
\hline Cost of poultry slaughter $\left(L_{1}\right)$ & $\begin{array}{l}\text { Cost per animalxnumber } \\
\text { of poultry killed }\end{array}$ \\
\hline \multicolumn{2}{|l|}{$\begin{array}{l}\text { Cost of closing live poultry } \\
\text { markets }\left(L_{2}\right)\end{array}$} \\
\hline Cost of live poultry sales $\left(\mathrm{L}_{21}\right)$ & $\begin{array}{l}\text { Live poultry sales per } \\
\text { dayxcost per } \\
\text { animalxnumber of days }\end{array}$ \\
\hline Cost of market-stall leases $\left(L_{22}\right)$ & $\begin{array}{l}\text { Cost of lease per stall } \\
\text { per day } \times \text { number of } \\
\text { stalls } \times \text { number of days }\end{array}$ \\
\hline
\end{tabular}

(formula 4). Production capability weights were calculated considering the different production capabilities at different ages. The following weights were used according to the literature: 0.15 at age $0-14$ years, 0.75 at age $15-44$ years, 0.8 at age $45-59$ years and 0.1 at age $60+$ years $^{20}$

$$
\begin{aligned}
\text { Cost of DALYs }= & \text { DALYs } \times \text { per }- \text { capita GDP } \\
& \times \text { weight of production capability }
\end{aligned}
$$

As mentioned above, direct PIL can be calculated using formula 5

$$
\mathrm{PIL}=\mathrm{L}_{1}+\mathrm{L}_{2}
$$

where $\mathrm{L}_{1}$ is the loss from poultry slaughter and $\mathrm{L}_{2}$ is the loss from the closing of live poultry markets, which includes lost sales of live poultry $\left(\mathrm{L}_{21}\right)$ and fees for market-stall leases $\left(\mathrm{L}_{22}\right)$. A cost formula was constructed for the estimate of PIL (table 2).

\section{RESULTS}

\section{Epidemiological characteristics of case categories}

A total of 131 confirmed H7N9 cases in 10 provinces in China were mapped as individual points based on detailed addresses (figure 2). Most of the patients $(81 \%$ ) were located in Jiangsu, Shanghai and Zhejiang Provinces. Most of the cases $(73 \%$ or above) in the 10 provinces were severe. There were 25 mild cases, 56 severe cases without death, 39 severe cases with death and 11 unknown cases without death in China through 31 May 2013.

Online supplementary figure S1 shows the rate, direction and scope of H7N9 spread. Each ellipse covers 95\% of the incident cases for 1 week. The location of the first week of H7N9 onset was Shanghai. Over the next few weeks, the epidemic spread to Jiangsu and Zhejiang Provinces and continued to grow. The virus spread quickly from the northwest to the north and south regions.

The onset of most H7N9 cases was relatively clustered. Within the total event timeframe (19 February and 21 May 2013), $74 \%$ of the cases were infected between 28 March and 17 April 2013 (see online supplementary figure S2). Severe cases with death were found in the initial and intermediate stages. The median age of patients with

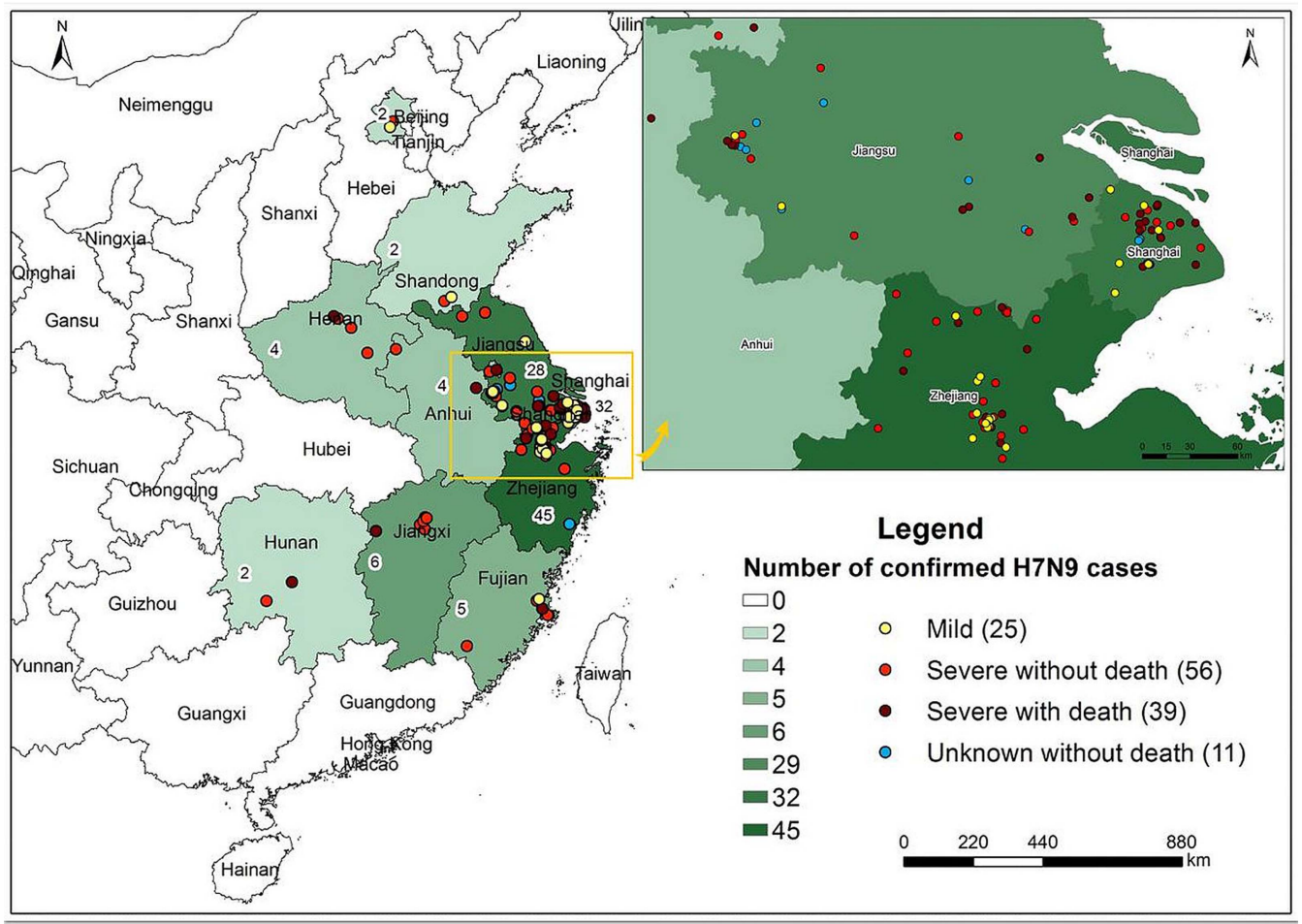

Figure 2 Spatial distribution of the 131 confirmed H7N9 cases, presenting the spatial distribution of the 131 confirmed H7N9 cases by severity in China. Mild, severe without death, severe with death and unknown without death cases are distinguished by different colours. The points are mapped based on the coordinates of the addresses. Areas with a high density of cases are magnified in the top right corner. The map was drawn using the ArcGIS 10.0 software). 
confirmed H7N9 virus infection was 61 years (range, 391 years). Severe symptoms tended to occur in older people. The median age of patients who were severely ill without death was 60 years, whereas the median age of patients who were severely ill with death was 69 years. The number of mild cases was distributed in all age groups $<80$ years (see online supplementary figure S3).

\section{Direct medical costs for confirmed H7N9 cases}

After the confirmed H7N9 cases occurred in China, the patient's clinical manifestations, examinations and treatments were published, ${ }^{6}$ which allowed us to estimate direct medical costs using a cost model. We separated the examination data into examinations conducted in the ward and examinations conducted in the ICU, as the latter were more frequent. The main treatments for confirmed H7N9 cases were selected. Three main factors were considered in our cost formula: cost per day, number of days and number of patients. For the cost-per-day estimation, we selected a Grade-III Class-A hospital (general large-scale hospital in China). Cost per day was obtained from the hospital financial officers and hospital doctors based on the average cost of patients with the same treatments from 1 January 2013 to 31 May 2013 in this hospital (online supplementary table S1). Differences in costs among the regions in China were approximately $10 \%$.

The mean number of days and number of cases were estimated from a subset of the investigated cases (table 3). Data regarding hospital stay were available for 11 of the 25 mild cases, 19 of the 56 severe cases without death and 19 of the 39 severe cases with death. The mean length of stay was 9 days for mild cases, 18 days for severe cases without death and 20 days for severe cases with death. Data on the duration of ICU stay were available for 10 of the 56 severe cases without death and 11 of the 39 severe cases with death. Severe cases without death stayed in the ICU for a mean of 12 days, whereas severe cases with death stayed for a mean of 16 days. We assumed that the mean hospital stay of severe cases with complications was equal to the length of the ICU stay, although complications might occur incrementally. The mean duration of treatments was estimated based on a subset of investigated patients, except for glucocorticoids and intravenous immunoglobulin, for which estimates were obtained from professional experience. Treatment for complications required drugs and examinations in addition to the treatments listed above. Treatment was described for 111 confirmed H7N9 cases, along with the proportion of patients who received each treatment. ${ }^{8}$ We assumed that the proportions were generalisable to all cases because it covered $85 \%$ of cases.

Online supplementary table S2 is a summary of all direct medical costs. The total cost for all 131 patients with confirmed H7N9 virus infection was $¥ 16422535$ (US\$2 627606 ). The mean cost per patient was ¥10 117 (US\$1619) for mild patients, ¥139 323 (US\$22 292) for severe cases without death and ¥205976 (US\$32 956) for severe cases with death. The mean cost per day was $¥ 1124$ (US\$180) for a mild case, ¥8293 (US\$1327) for a severe case without death and $¥ 8978$ (US\$1437) for a severe case with death. As the severity of the illness increased, the costs increased correspondingly.

\section{Cost of DALYs for H7N9}

A total of 39 deaths from confirmed H7N9, including 30 men and 9 women, were reported from the National Health and Family Planning Commission of China by 31 May 2013. See online supplementary table S3 for more details on the number of cases in each age group. The total YLLs were 676.89. There were 131 H7N9 cases, including 25 mild cases, 95 severe cases and 11 of unknown category (assumed to be moderate). The YLD calculations were based on the case category. Total YLDs were 1.064 (see online supplementary table S4). DALYs combined the time lived with disability and the time lost due to premature mortality; thus, DALYs were 677.848 for all confirmed patients with H7N9. We adopted 2012 per capita GDP for the 10 provinces and estimated the cases adjusted per capita GDP ( $¥ 65655$ or US $\$ 10505$ ). By calculating the weight of production capability for each age group, we obtained the average weight of production capability to be 0.39 for all confirmed H7N9 cases. The total cost of DALYs was $¥ 17356561$ (US\$2 777050 ) according to formula 4.

\section{Poultry industry losses}

PIL were estimated for three categories (figure 3) (1) 27 prefectures with confirmed H7N9 cases (region 1, brown in figure 3), (2) 10 affected provinces (region 2, yellow in figure 3) and (3) eight non-affected adjacent provinces (region 3, shadowed in figure 3 ).

Three types of losses were calculated for region 1: losses from poultry slaughter, lost live poultry sales and fees for market-stall leases. In the 10 affected provinces (region 2), in addition to the losses in region 1, the losses arose mainly from closing down live poultry markets in each province. These two losses were then summed to estimate PIL caused by H7N9 outbreaks. Most of the main live poultry markets in the affected provinces (figure 3) were obtained from Google Earth; the retail locations were excluded.

PIL in eight non-affected adjacent provinces (region 3) were also calculated as potential economic losses. The direct PIL of 27 prefectures for the H7N9 cases are described in detail in table 4 .

The cost of closing down live poultry markets includes the lost live poultry sales and fees for market-stall leases. The cost of lost live poultry sales was calculated according to the daily live poultry sales, the cost per animal (assumed to be $¥ 10$ or US\$1.6 in this study) and the number of days the market was closed. The cost of market-stall leases was calculated based on the average lease per stall per day in the corresponding city, the number of stalls and the number of days the market was closed in each city. The cost of poultry slaughter was obtained from the number of poultry slaughtered and the cost per animal. The number of days the market was closed was counted through 31 May 
Table 3 Driver measurement

\begin{tabular}{|c|c|c|c|c|c|c|c|c|c|}
\hline \multirow[b]{2}{*}{ Category } & \multicolumn{2}{|l|}{ Mild } & \multicolumn{2}{|c|}{ Severe without death } & \multicolumn{2}{|l|}{ Severe with death } & \multicolumn{2}{|c|}{ death } & \multirow[b]{2}{*}{$\begin{array}{l}\text { Reference } \\
\text { proportion of } \\
\text { patients (\%)† }\end{array}$} \\
\hline & $\begin{array}{l}\text { Mean number of } \\
\text { days (number of } \\
\text { cases } \\
\text { investigated/total } \\
\text { cases) }\end{array}$ & $\begin{array}{l}\text { Number } \\
\text { of cases }\end{array}$ & $\begin{array}{l}\text { Mean number of } \\
\text { days (number of } \\
\text { cases } \\
\text { investigated/total } \\
\text { cases) }\end{array}$ & $\begin{array}{l}\text { Number } \\
\text { of cases }\end{array}$ & $\begin{array}{l}\text { Mean number of } \\
\text { days (number of } \\
\text { cases } \\
\text { investigated/total } \\
\text { cases) }\end{array}$ & $\begin{array}{l}\text { Number } \\
\text { of cases }\end{array}$ & $\begin{array}{l}\text { Mean } \\
\text { number } \\
\text { of days }{ }^{*}\end{array}$ & $\begin{array}{l}\text { Number } \\
\text { of cases }\end{array}$ & \\
\hline Hospital stay & $9(11 / 25)$ & 25 & $18(19 / 56)$ & 55 & $20(19 / 39)$ & 38 & 14 & 11 & 98.2 \\
\hline ICU stay & 0 & 0 & $12(10 / 56)$ & 55 & $16(11 / 39)$ & 38 & 6 & 7 & 76.6 \\
\hline \multicolumn{10}{|l|}{ Treatment } \\
\hline Antiviral & 7 (3/25) & 24 & $7(20 / 56)$ & 54 & $11(11 / 39)$ & 38 & 7 & 11 & 97.3 \\
\hline Antibiotics & $8(4 / 25)$ & 17 & $11(21 / 56)$ & 40 & $14(16 / 39)$ & 28 & 9 & 8 & 71.2 \\
\hline Other drugs & $9(11 / 25)$ & 25 & $12(10 / 56)$ & 55 & $16(11 / 39)$ & 38 & 11 & 11 & 98.2 \\
\hline Glucocorticoids & 0 & 0 & $7 \ddagger$ & 43 & $7 \ddagger$ & 30 & 4 & 8 & 62.2 \\
\hline Intravenous & 0 & 0 & $5 \ddagger$ & 37 & $5 \ddagger$ & 26 & 3 & 7 & 53.2 \\
\hline \multicolumn{10}{|l|}{ immunoglobulin } \\
\hline Oxygen therapy & $9(11 / 25)$ & 25 & $18(19 / 56)$ & 56 & $20(19 / 39)$ & 39 & 9 & 11 & 100.0 \\
\hline \multicolumn{10}{|l|}{ Mechanical ventilation } \\
\hline Non-invasive & 0 & 0 & $9(7 / 56)$ & 19 & $3(6 / 39)$ & 13 & 5 & 4 & 27.9 \\
\hline Invasive & 0 & 0 & $8(7 / 56)$ & 41 & $10(15 / 39)$ & 28 & 4 & 8 & 58.6 \\
\hline & 0 & 0 & $4 \ddagger$ & 11 & $4 \ddagger$ & 7 & 2 & 2 & 15.3 \\
\hline \multicolumn{10}{|l|}{$\begin{array}{l}\text { Artificial-liver-support-system } \\
\text { therapy }\end{array}$} \\
\hline $\begin{array}{l}\text { Continuous } \\
\text { renal-replacement therapy }\end{array}$ & 0 & 0 & $7 \ddagger$ & 18 & $7 \ddagger$ & 13 & 4 & 4 & 26.1 \\
\hline ECMO & 0 & 0 & $6(1 / 56)$ & 12 & $7(2 / 39)$ & 9 & 3 & 2 & 18.0 \\
\hline \multicolumn{10}{|l|}{ Complications } \\
\hline ARDS & 0 & 0 & $12(10 / 56)$ & 50 & $16(11 / 39)$ & 35 & 6 & 10 & 71.2 \\
\hline Shock & 0 & 0 & $12(10 / 56)$ & 18 & $16(11 / 39)$ & 13 & 6 & 4 & 26.1 \\
\hline Acute kidney injury & 0 & 0 & $12(10 / 56)$ & 11 & $16(11 / 39)$ & 8 & 6 & 2 & 16.2 \\
\hline Rhabdomyolysis & 0 & 0 & $12(10 / 56)$ & 7 & $16(11 / 39)$ & 5 & 6 & 1 & 9.9 \\
\hline Other costs & $9(11 / 25)$ & 25 & $18(19 / 56)$ & 55 & $20(19 / 39)$ & 38 & 14 & 11 & 98.2 \\
\hline
\end{tabular}

${ }^{*}$ Mean number of days for patients with unknown without death was estimated as the average number of days for mild and severe cases without death.

†Referenced from the literature 'Clinical Findings in 111 Cases of Influenza A (H7N9) Virus Infection'.6

łBased on professional experience.

ARDS, acute respiratory distress syndrome; EMCO, extracorporeal membrane oxygenation; ICU, intensive care unit. 


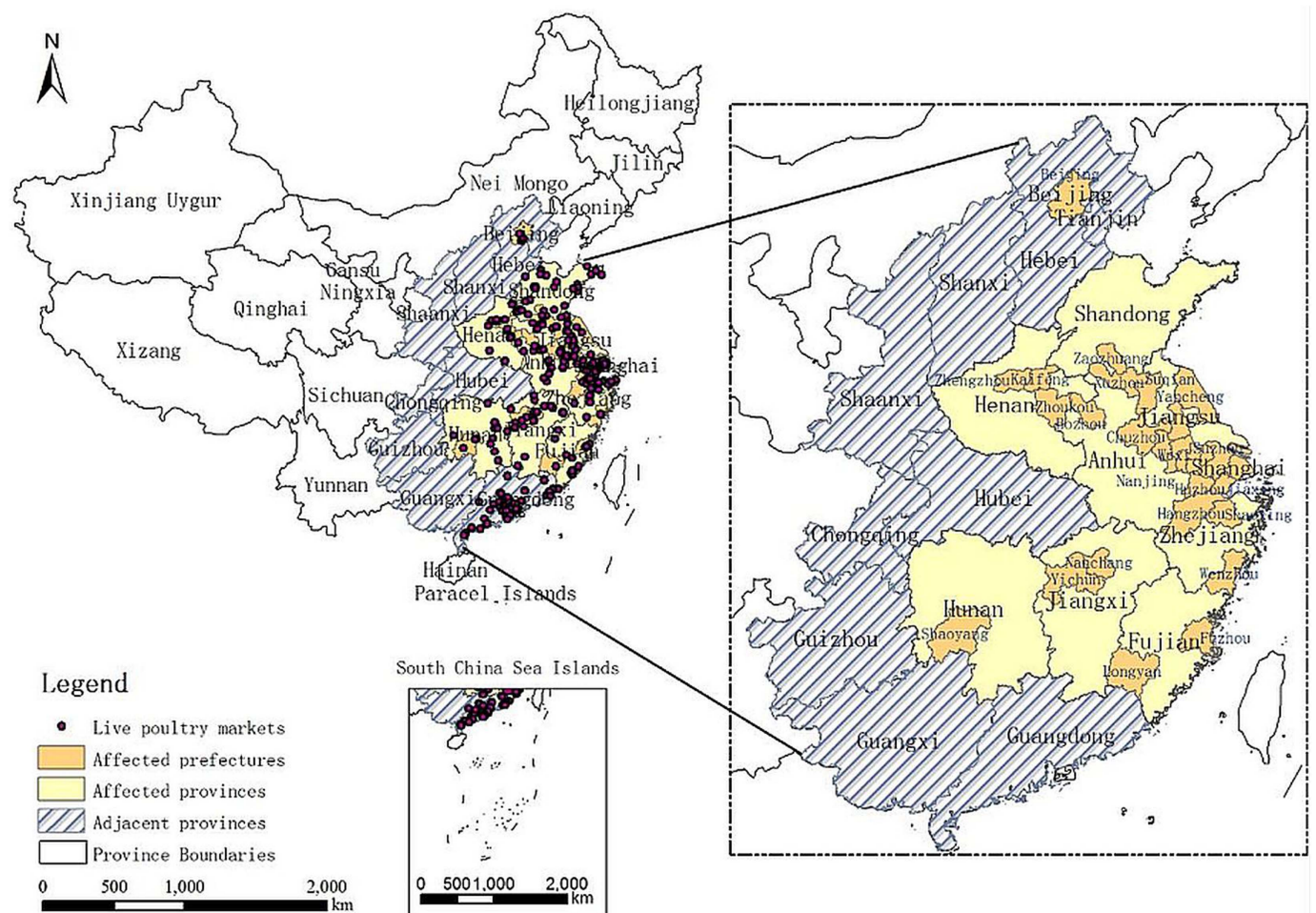

Figure 3 Three regions for poultry industry loss estimates, presenting estimated poultry industry losses for three categories including 27 prefectures, 10 affected provinces and 8 non-affected adjacent provinces. Points represent most of the main live poultry markets, which were obtained from Google Earth excluding the retail locations. The map was drawn using the ArcGIS 10.0 software.

because only one confirmed H7N9 case had occurred since then. The total PIL in the 10 affected provinces, including 27 prefectures with H7N9 cases, are listed in table 5. The PIL of each province are presented in online supplementary figure S4.

China's poultry industry suffered direct losses amounting to $¥ 7.75$ billion (US\$1.24) from when the first case of H7N9 was confirmed through 31 May 2013. Losses from the live poultry trade accounted for $98 \%$ of the total losses. Although it had only a few H7N9 cases, Shandong Province ranked first in losses among all 10 provinces at ¥1.81 billion (US\$0.29); Jiangsu, Henan and Anhui ranked next with $¥ 1.28$ billion(US $\$ 0.20$ ), $¥ 1.15$ billion(US $\$ 0.18$ ) and $¥ 1.14$ billion(US $\$ 0.18$ ), respectively. These provinces have large poultry markets. Zhejiang Province had the highest number of confirmed cases; however, the losses in that region were not very high, as the sales of live poultry were lower. Strict prevention and control measures, such as daily cleaning of the market, weekly disinfection of the market and monthly closings of the live market were conducted in Guangdong Province, which reported no H7N9 cases until 31 May 2013 during the emergency response. These prevention and control measures affected the poultry industry. For this reason, the PIL in Guangdong Province are also given in table 5.

Owing to timely control measures, the H7N9-affected regions were limited to 27 prefectures in 10 provinces in
China. In this study, the potential economic risks were also calculated for the eight non-affected adjacent provinces (region 3, shadowed in figure 3). Online supplementary table S5 shows that the potential losses to the poultry industry in those regions amounted to ¥3.6 billion (US\$0.58).

\section{DISCUSSION}

This study was based on illness severity and spatiotemporal aspects of the recent avian-origin influenza A (H7N9) infection. We assumed that cases of the same severity resulted in similar medical costs. Therefore, mild cases, severe cases without death, severe cases with death and unknown cases without death were estimated separately by calculating the mean number of days, number of cases and cost per day.

Compared with the PIL, direct medical losses and DALY losses were relatively small. To a large extent, the small number of patients in the H7N9 outbreak in China was due to quick and effective intervention, which prevented a pandemic. ${ }^{21}$ The estimate of direct medical costs and DALY costs, particularly the mean cost per patient and mean cost per day for different case categories, can be used to guide those counties in which no cases occurred during prevention and control of H7N9. DALY per H7N9 case (5176 DALYs/1000 cases) was much higher than most of other respiratory infectious diseases though DALYs per 100000 population (2.23 
Table 4 Poultry-industry losses of 27 prefectures with H7N9 cases

\begin{tabular}{|c|c|c|c|c|c|c|c|}
\hline \multirow{2}{*}{$\begin{array}{l}\text { Affected } \\
\text { provinces } \\
\text { (number of } \\
\text { cases) }\end{array}$} & \multirow{2}{*}{$\begin{array}{l}\text { Affected } \\
\text { prefectures } \\
\text { (number of } \\
\text { cases) }\end{array}$} & \multirow[b]{2}{*}{ Date } & \multicolumn{4}{|c|}{ Cost of closing live poultry markets } & \multirow{2}{*}{$\begin{array}{l}\text { Cost of } \\
\text { poultry } \\
\text { slaughter } \\
\left(¥ 10^{4}\right)\end{array}$} \\
\hline & & & $\begin{array}{l}\text { Live poultry } \\
\text { sales per } \\
\text { day }\left(10^{4}\right)\end{array}$ & $\begin{array}{l}\text { Number } \\
\text { of days }\end{array}$ & $\begin{array}{l}\text { Cost of live } \\
\text { poultry } \\
\text { sales }\left(¥ 10^{4}\right)\end{array}$ & $\begin{array}{l}\text { Market-stall } \\
\text { leases }\left(¥ 10^{4}\right)\end{array}$ & \\
\hline Beijing (2) & Beijing (2) & 4.13 & 3.00 & 49 & 1470.00 & 6.93 & 0.50 \\
\hline Shanghai (32) & Shanghai (32) & 4.05 & 11.94 & 57 & 6805.80 & 1703.16 & 20.54 \\
\hline \multirow[t]{9}{*}{ Jiangsu (29) } & Wuxi (4) & 4.09 & 12.87 & 53 & 6821.10 & 527.40 & 0.40 \\
\hline & Yancheng (1) & 4.15 & 8.18 & 47 & 3844.60 & 387.11 & 5.00 \\
\hline & Nanjing (12) & 4.06 & 8.91 & 56 & 4989.60 & 567.84 & 8.00 \\
\hline & Zhenjiang (1) & 4.09 & 8.55 & 53 & 4531.50 & 342.12 & 0.31 \\
\hline & Suzhou (7) & 4.08 & 17.73 & 54 & 9574.20 & 265.03 & 0.01 \\
\hline & Yangzhou (1) & 4.15 & 11.52 & 47 & 5414.40 & 180.17 & 0.20 \\
\hline & Xuzhou (1) & 4.24 & 14.80 & 38 & 5624.00 & 380.30 & 0.10 \\
\hline & Changzhou (1) & 4.11 & 8.94 & 51 & 4559.40 & 167.71 & 1.30 \\
\hline & Suqian (1) & 4.02 & 10.14 & 60 & 6084.00 & 200.00 & 0.10 \\
\hline \multirow[t]{5}{*}{ Zhejiang (45) } & Huzhou (12) & 4.11 & 6.14 & 51 & 3131.40 & 269.79 & 0.70 \\
\hline & Shaoxing (1) & 4.22 & 5.31 & 40 & 2124.00 & 585.14 & 10.00 \\
\hline & Hangzhou (29) & 4.15 & 12.48 & 47 & 5865.60 & 1200.20 & 24.66 \\
\hline & Jiaxing (2) & 4.19 & 6.97 & 43 & 2997.10 & 1565.77 & 10.00 \\
\hline & Wenzhou (1) & 4.21 & 7.02 & 41 & 2878.20 & 49.78 & 0.50 \\
\hline \multirow[t]{2}{*}{ Auhui (4) } & Bozhou (1) & 4.09 & 2.89 & 53 & 1531.70 & 100.33 & 10.00 \\
\hline & Chuzhou (3) & 3.30 & 6.19 & 63 & 3899.70 & 65.01 & 0.72 \\
\hline \multirow[t]{2}{*}{ Fujian (5) } & Longyan (1) & 5.07 & 6.73 & 25 & 1682.50 & 77.40 & 0.82 \\
\hline & Fuzhou (4) & 4.29 & 6.61 & 33 & 2181.30 & 287.76 & 100.00 \\
\hline \multirow[t]{2}{*}{ Jiangxi (6) } & Nanchang (5) & 4.26 & 12.62 & 36 & 4543.20 & 45.72 & 0.10 \\
\hline & Yichun (1) & 4.29 & 10.46 & 33 & 3451.80 & 14.09 & 0.08 \\
\hline \multirow[t]{3}{*}{ Henan (4) } & Zhoukou (1) & 4.16 & 13.59 & 46 & 6251.40 & 18.28 & 1.60 \\
\hline & Kaifeng (1) & 4.15 & 9.22 & 47 & 4333.40 & 14.81 & 1.80 \\
\hline & Zhengzhou (2) & 4.15 & 9.01 & 47 & 4234.70 & 20.68 & 3.90 \\
\hline Hunan (2) & Shaoyang (2) & 4.28 & 7.80 & 34 & 2652.00 & 70.10 & 100.00 \\
\hline Shandong (2) & Zaozhuang (2) & 4.24 & 21.20 & 38 & 8056.00 & 52.36 & 0.66 \\
\hline Total cost $\left(¥ 10^{4}\right)$ & 128999.59 & & & & & & \\
\hline Total cost $\left(\$ 10^{4}\right)^{*}$ & 20639.93 & & & & & & \\
\hline
\end{tabular}

DALYs based on affected county population) were lower than most of the infectious diseases according to the 2010 GBD study. ${ }^{22}$ A comparison to outbreaks of other infectious diseases (with similar clinical symptoms) was also considered in this report. The healthcare cost per patient with severe acute respiratory syndrome (SARS)

Table 5 Total poultry industry losses in the 10 affected provinces

\begin{tabular}{|c|c|c|c|c|c|}
\hline $\begin{array}{l}\text { Affected } \\
\text { provinces }\end{array}$ & $\begin{array}{l}\text { Cost of live poultry } \\
\text { sales }\left(¥ 10^{4}\right)\end{array}$ & $\begin{array}{l}\text { Market-stall leases } \\
\left(¥ 10^{4}\right)\end{array}$ & $\begin{array}{l}\text { Cost of poultry } \\
\text { slaughter }\left(¥ 10^{4}\right)\end{array}$ & $\begin{array}{l}\text { Total cost } \\
\left(¥ 10^{4}\right)\end{array}$ & $\begin{array}{l}\text { Total cost } \\
\left(\text { US } \$ 10^{4}\right)\end{array}$ \\
\hline Beijing & 14553.98 & 291.06 & 0.5 & 14845.54 & 2394.59 \\
\hline Shanghai & 6805.8 & 1703.16 & 20.54 & 8529.5 & 1375.81 \\
\hline Jiangsu & 124485.53 & 3181.5 & 25.62 & 127692.66 & 20596.83 \\
\hline Zhejiang & 29982.14 & 2444.4 & 45.36 & 32471.9 & 5237.72 \\
\hline Anhui & 113309.59 & 1113.01 & 11.52 & 114434.12 & 18458.22 \\
\hline Fujian & 16723.29 & 509.04 & 100.82 & 17333.15 & 2795.84 \\
\hline Jiangxi & 40832.88 & 255.36 & 0.18 & 41088.42 & 6627.56 \\
\hline Henan & 114473.97 & 73.09 & 7.3 & 114554.36 & 18477.62 \\
\hline Hunan & 32301.37 & 433.25 & 100 & 32834.62 & 5296.22 \\
\hline Shandong & 180421.92 & 402.76 & 0.66 & 180825.34 & 29167.13 \\
\hline Guangdong & 88827.4 & 1808.59 & 99.36 & 90735.35 & 14635.61 \\
\hline Total cost $\left(¥ 10^{4}\right)$ & 762717.86 & 12215.21 & 411.87 & 775344.94 & 125063.14 \\
\hline Total cost $\left(\$ 10^{4}\right)$ & 123026.39 & 1970.31 & 66.43 & 125063.14 & 2394.59 \\
\hline
\end{tabular}

Date on which the live poultry markets were closed varied among cities/counties. the dates when the first case of H7N9 was confirmed were adopted for estimating the total amount of poultry industry losses in each affected province. 
in Beijing was $¥ 17150$ (US\$1886), whereas the average medical cost per patient with H7N9 was ¥125 363 (US $\$ 20058$ ) because of the higher death rate of patients with H7N9 and use of more expensive modern medical devices. $^{23}$

As of the end of May, China's poultry industry suffered direct losses amounting to $¥ 7.75$ billion (US\$1.24), including the cost of closing live poultry markets and slaughtering poultry in the 10 affected provinces. PIL were estimated at three levels: 27 prefectures with confirmed H7N9 cases, 10 affected provinces and 8 nonaffected adjacent provinces. The outbreak of H7N9 may reduce the demand for poultry products in other regions of China due to public perception. These effects were not considered in this study. The cost of closing down the live poultry markets and the cost of poultry slaughter were calculated as direct PIL. We assumed that the cost per animal was $¥ 10$ (US\$1.6) and the date for the end of closing the live poultry markets was 31 May 2013 because there has been few confirmed H7N9 cases since then. Losses from the live poultry industry accounted for $98 \%$ of the total losses, with the lost sales of live poultry constituting the majority of that amount. Strict prevention and control measures have been enacted in Guangdong Province, which had few reported H7N9 cases. This finding will be significant for similar cases in the future. Owing to timely control measures, the effects of the outbreak were limited to 27 prefectures in 10 provinces in China.

Our study had several limitations. First, there were 11 confirmed H7N9 cases without death whose case categories were unknown. The cost estimate for these unknown patients was replaced by the average cost of mild and severe cases without death. Second, in the cost model, some of the data (eg, the mean number of days of extracorporeal membrane oxygenation for severe without death cases) were obtained from a small proportion of investigated cases, which could result in an estimation bias. Third, the direct medical cost did not include opportunity cost, ${ }^{24}$ the cost that is incurred because a limited resource is used to treat a preventable disease and cannot therefore be used to treat another disease. $^{25}$ The medical practitioner's salary, research funding and loss of working time for family numbers of patients with H7N9 were excluded from our study. Fourth, estimates of direct medical costs per day might show large differences for specific cases because the drug cost could grow considerably if imported and nutritional drugs were used. We considered only the average severity for patients in the ward and ICU. Fifth, 17 patients were still in the hospital on 28 May 2013 according to the literature. ${ }^{26}$ The mean numbers of days in the ward and ICU for severe cases and their death rate were thus underestimated. Some of the mild cases may not have been reported, which also resulted in underestimating the cost. Sixth, we considered only direct losses from closing down live poultry markets and large-scale poultry slaughter, which could be estimated accurately and quickly. This estimate was useful for early control and decision-making; however, other losses involved in the livestock-production chain, such as increased breeding costs, poultry seeding, the prices of poultry meat and eggs and the decreased production of poultry-feather industries should be considered in further studies. ${ }^{27}$

In conclusion, we present a rapid, operable and accurate framework for estimating the burden of human infections from H7N9. This framework could be used in a BOD analysis of future H7N9 or similar outbreaks. The results including direct and indirect costs provide fundamental information for researchers and public and policymakers to support timely and effective interventions. Future study may focus on the costeffectiveness analysis of poultry industry shut down, earlier diagnosis and effective treatments of patients based on more detailed investigation information.

\section{Author affiliations}

${ }^{1}$ National Center for Public Health Surveillance and Information Services, Chinese Center for Disease Control and Prevention, Beijing, China

${ }^{2}$ State Key Laboratory of Resources and Environmental Information System, Institute of Geographical Sciences and Natural Resources Research, Chinese Academy of Sciences, Beijing, China

${ }^{3}$ The 2nd Affiliated Hospital of Harbin Medical University, Harbin, China

${ }^{4}$ University of Chinese Academy of Sciences, Beijing, China

${ }^{5}$ School of Public Health, Harbin Medical University, Harbin, China

${ }^{6}$ College of Geoscience and Surveying Engineering, China University of Mining

\& Technology (Beijing), Beijing, China

${ }^{7}$ Chinese Center for Disease Control and Prevention, Beijing, China

Acknowledgements We thank Zijian Feng and Qun Li (Public Health Emergency Center, Chinese Center for Disease Control and Prevention) for data sharing and valuable suggestions. We thank Maigeng Zhou (National Center for Chronic and Non-communicable Disease Control and Prevention, Chinese Center for Disease Control and Prevention) for help with statistical analysis.

Contributors $X Q$ and GFG designed and supervised the study, and applied the grants. XQ, DJ, HW, DZ, JM, JF, JQ, YS, GW and KX collected data. XQ, DJ, JF, SY, YM, YH, LX, YL, YW, XS and GF analysed data. QZ, MW, LX and YL took literature search; $X Q$ and DJ drafted the manuscript. All authors participated in the conception and design of the report, and contributed to review and revision and have seen and approved the final version.

Funding National Basic Research Programme of China (973 Programme) (2012CB955504).

\section{Competing interests None.}

Provenance and peer review Not commissioned; externally peer reviewed.

Data sharing statement No additional data are available.

Open Access This is an Open Access article distributed in accordance with the Creative Commons Attribution Non Commercial (CC BY-NC 3.0) license, which permits others to distribute, remix, adapt, build upon this work noncommercially, and license their derivative works on different terms, provided the original work is properly cited and the use is non-commercial. See: http:// creativecommons.org/licenses/by-nc/3.0/

\section{REFERENCES}

1. Li Q, Zhou L, Zhou M, et al. Preliminary report: epidemiology of the avian influenza A (H7N9) outbreak in China. N Engl J Med 2013;24:1-11.

2. Chen $\mathrm{Y}$, Liang $\mathrm{W}$, Yang $\mathrm{S}$, et al. Human infections with the emerging avian influenza A H7N9 virus from wet market poultry: clinical 
analysis and characterisation of viral genome. Lancet 2013;381:1916-25.

3. Bao CJ, Cui LB, Zhou MH, et al. Live-animal markets and influenza A (H7N9) virus infection. N Engl J Med 2013;368:2337-39.

4. Wu Y, Gao GF. Lessons learnt from the human infections of avian-origin influenza $\mathrm{A} \mathrm{H7N9}$ virus: live free markets and human health. Sci China Life Sci 2013;56:493-4.

5. Li J, Yu X, Pu X, et al. Environmental connections of novel avian-origin $\mathrm{H} 7 \mathrm{~N} 9$ influenza virus infection and virus adaptation to the human. Sci China Life Sci 2013;56:485-92.

6. Liu D, Shi W, Shi $Y$, et al. Origin and diversity of novel avian influenza A H7N9 viruses causing human infection: phylogenetic, structural, and coalescent analyses. Lancet 2013;381:1926-32.

7. Gao R, Cao B, Hu Y, et al. Human infection with a novel avian-origin influenza A (H7N9) virus. N Engl J Med 2013;368:1888-97.

8. Gao HN, Lu HZ, Cao B, et al. Clinical findings in 111 cases of influenza A (H7N9) virus infection. N Engl J Med 2013;368:2277-85.

9. Murray CJ, Ezzati M, Flaxman AD, et al. GBD 2010: design, definitions, and metrics. Lancet 2012;380:2063-6.

10. Murray CJ, Frenk J, Piot P, et al. GBD 2.0: a continuously updated global resource. Lancet 2013;382:9-11.

11. Diagnostic and treatment protocol for human infections with avian influenza A (H7N9) (2nd edition, 2013), 2013. http://www.moh.gov. $\mathrm{cn} /$ mohgjhzs/s7952/201304/98ceede1daf74a45b1105f18c4e23ece. shtml (accessed 10 Jun 2013).

12. Life expectancy: Life tables China, 2011. http://apps.who.int/gho/ data/view.main.60340?lang=en (accessed 10 Jun 2013).

13. GBD 2010 Disability Weights 2010. http://ghdx.healthmetricsand evaluation.org/global-burden-disease-study-2010-gbd-2010-datadownloads (accessed 10 Jun 2013)

14. China Animal Industry Yearbook. Beijing: China Agricultural Press, 2012.

15. Statistical Yearbook of China Commodity Exchange Market. Beijing: Foreign Economy Statistics Division, National Statistics Bureau; Market Operation and Consumer Promotion Divison of Ministry of Commerce; Information Department of Commerce Association of China, 2012.

16. Lipscomb J, Yabroff KR, Brown ML, et al. Health care costing: data, methods, current applications. Med Care 2009;47:S1-6.
17. Allorto NL, Clarke DL, Thomson SR. A cost model case comparison of current versus modern management of burns at a regional hospital in South Africa. Burns 2011;37:1033-7.

18. Clement Nee Shrive FM, Ghali WA, Donaldson C, et al. The impact of using different costing methods on the results of an economic evaluation of cardiac care: microcosting vs gross-costing approaches. Health Econ 2009;18:377-88.

19. Polinder S, Haagsma JA, Stein C, et al. Systematic review of general burden of disease studies using disability-adjusted life years. Popul Health Metr 2012;10:21.

20. Du L, Wang J, Luo B, et al. Research on disease burden of SARS patients in Guangzhou city. Chinese J Public Health 2007; 23:379-81

21. $\mathrm{Yu} \mathrm{H}, \mathrm{Wu} \mathrm{J}$, Cowling B, et al. Effect of closure of live poultry markets on poultry-to-person transmission of avian influenza A H7N9 virus: an ecological study. Lancet 2013 doi:10.1016/S0140-6736(13) 61904-2.

22. Murray CJ, Vos T, Lozano R, et al. Disability-adjusted life years (DALYs) for 291 diseases and injuries in 21 regions, 1990-2010: a systematic analysis for the Global Burden of Disease Study 2010. Lancet 2012;380:2197-223.

23. Xiao F, Chen BW, Wu YF, et al. Analysis on the cost and its related factors of clinically confirmed severe acute respiratory syndrome cases in Beijing. Zhonghua Liu Xing Bing Xue Za Zhi 2004; 25:312-16.

24. O'Shea C. Opportunity cost. Aust Fam Physician 2011;40:261.

25. Kong V, Aldous $\mathrm{C}$, Handley $\mathrm{J}$, et al. The cost effectiveness of early management of acute appendicitis underlies the importance of curative surgical services to a primary healthcare programme. Ann $R$ Coll Surg Engl 2013;95:280-4.

26. $\mathrm{Yu} \mathrm{H}$, Cowling BJ, Feng $\mathrm{L}$, et al. Human infection with avian influenza A H7N9 virus: an assessment of clinical severity. Lancet 2013;382:138-145.

27. FAO. Highly pathogenic avian influenza in Mexico (H7N3)-a significant threat to poultry production not to be underestimated. Empres Watch: EMPRES WATCH, 2012. http://www.fao.org/docrep/ 016/an395e/an395e.pdf (accessed 15 Jun 2013). 